\title{
Remediation Experimental of Chromium- Contaminated Soft Soil by Temperature-Controlled Electric Combined Leaching
}

\author{
Qian Baoyuan ${ }^{1 *}$, Wang Aihua', Wang Yan $^{2}$ and Liu Ganbin ${ }^{2}$ \\ ${ }^{1}$ Ningbo Ningda Foundation treatment Technology Co., Ltd., Ningbo, China \\ ${ }^{2}$ Institute of Geotechnical Engineering, Ningbo University, Ningbo, China
}

*Corresponding author: Qian Baoyuan, Ningbo Ningda Foundation treatment

Technology Co., Ltd., Ningbo, China.

Received Date: July 27, 2020

Published Date: August 18, 2020

\begin{abstract}
It is often inefficient and difficult to achieve the ideal remediation effect using a single remediation technology to repair contaminated soil, so the combined remediation technology of temperature-controlled electric combined leaching has aroused people's interest. At present, it is widely used in chromium-contaminated soft soil.
\end{abstract}

Keywords: Chromium-contaminated soft soil; Electrokinetic remediation; Temperature-controlled

\section{Introduction}

Chromium has a series of reactions with soil, such as adsorption, complexation, reduction, oxidation and so on, which makes its existing form in soil different from its input form [1]. According to the continuous extraction method proposed by Tessier et al. [2], the forms of chromium in soil can be divided into the following five forms: exchangeable, carbonate-bound, iron- manganese oxidebound, organic-bound and residual. The remediation methods of chromium contaminated soil are roughly divided into physical remediation, chemical remediation, bioremediation and combined remediation, among which electrokinetic remediation is a clean and efficient remediation method of contaminated soil, which belongs to the physical and chemical remediation method. The Lasagna technology, which was first used in Kentucky in 1995, and the combined repair technology of Electro-KleanTM and electric adsorption used in Louisiana in the future, the electrochemical oxidation technology used in Germany, and the compound repair technology of EK-solar field used in a site in South Korea [3].
Scholars from all over the world have also carried out extensive experimental studies on the electrokinetic remediation of chromium-contaminated soil. In the 1990s, Ryan et al. [4] put forward the electrokinetic restoration method earlier, and Reddy et al. [5] studied the difference of electrokinetic remediation effect of different types of chromium contaminated soil. Kim et al. [6] conducted an experimental study on the electro remediation of muddy soil polluted by chromium, copper and lead. The results showed that the removal rate of heavy metals depended on their forms in the soil, and the removal rate of exchangeable and carbonate bound chromium reached 70\%. Reddy et al. [7] studied the effect of the initial form of chromium in soil on the effect of electrokinetic remediation test.

Al-Hamdan et al. [8] presented a systematic bench-scale laboratory study performed to assess the transient behavior of chromium, nickel, and cadmium in different soils during electrokinetic remediation. It is showed that in kaolin, the extent 
of Ni (II) and Cd (II) migration towards the cathode increased as the treatment time increased. Peng et al. [9] studied the effect of different electrolytes on electrokinetic remediation of muddy soil polluted by chromium and zinc. Distilled water, SDS solution and citric acid solution were used as electrolytes. After 5 days of electrokinetic remediation, the total removal rates of heavy metals were $20-51 \%, 26-65 \%$ and $34-69 \%$, respectively, and the removal rate of chromium was the highest when citric acid solution was used as electrolyte. Li et al. [10] proposed to use the method close to the anode to enhance the effect of electro remediation of chromium contaminated soil, that is, the anode moves $7 \mathrm{~cm}$ to the cathode every three days, which is beneficial to the desorption and dissolution of chromium, promote the dissociation of chromium from the soil, strengthen the migration ability of chromium in soil, and improve the removal efficiency of chromium in soil. The effects of acidification time, concentrations of acetic acid and citric acid on removal of chromium from soils were studied by changing the acidification pretreatment conditions, and then speciation analysis of the chromium was conducted to study the regularity of $\mathrm{Cr}$ in different speciation's [11]. The total chromium( $\mathrm{Cr}(\mathrm{T}))$ and hexavalent chromium( $\mathrm{Cr}(\mathrm{VI}))$ removal rates of the group acidized by citric acid( $0.9 \mathrm{~mol} / \mathrm{L})$ for five days were up to $26.97 \%$ and $77.66 \%$, respectively, while the $\mathrm{Cr}(\mathrm{T})$ and $\mathrm{Cr}(\mathrm{VI})$ removal rates of the group without acidification were $6.23 \%$ and $19.01 \%$, respectively. The experiments of Meng et al. [12] proved that acidification pretreatment can significantly improve the removal efficiency of chromium in soil in electrokinetic remediation experiments.

In addition, the citric acid fermentation broth was used to leach and repair the $\mathrm{Cr}-\mathrm{Cu}-\mathrm{Pb}$ contaminated soil, and the chromium removal rate was $43.7 \%$, which was higher than that obtained by using citric acid leaching solution [13]. Accordingly, the authors of this paper improved the temperature-controlled electric combined leaching remediation device based on the development of temperature-controlled electric remediation device. Then, the effects of the concentration of $\mathrm{Cr}$ (VI) and $\mathrm{Cr}$ (total), voltage, temperature and the type of leaching solution on the remediation of chromium-contaminated soil are considered and the remediation experiments of chromium-contaminated soil by soil electrokinetic, leaching and electrokinetic leaching were systematically carried out.

The temperature-controlled electric remediation device was used to carry out the remediation experiment on chromiumcontaminated soft soil. The factor that had the greatest influence on the removal rate of $\mathrm{Cr}(\mathrm{VI})$ in the contaminated soil was voltage, followed by temperature and the initial concentration of $\mathrm{Cr}$ (VI) in the soil. Under the applied voltage of $36 \mathrm{~V}$, the removal rate of $\mathrm{Cr}$ (VI) in each group was more than $96 \%$, and the highest removal rate of $\mathrm{Cr}$ (total) in the soil was $76 \%$.

After adopting the improvement measure of increasing the cross-sectional area of the conductive part of the bottom surface of the soil column, the electric combined leaching remediation experiment was carried out on the self-made chromium contaminated soft soil. The study shows that after the experiment, the removal rates of $\mathrm{Cr}$ (VI) and $\mathrm{Cr}$ (total) in the soil column are improved correspondingly: the removal rate of $\mathrm{Cr}$ (VI) in the soil column of each test group is more than 97\%.At low voltage and $15 \mathrm{~V}$, the removal rates of $\mathrm{Cr}$ (VI) and $\mathrm{Cr}$ (total) in the test group containing oxalic acid, sodium dodecylbenzene sulfonate and citric acid reached $99.6 \%$ and $89.4 \%, 99.2 \%$ and $89.6 \%, 98.1 \%$ and $80 \%$, respectively.

\section{Acknowledgement}

This research is supported by the Ningbo Science and Technology Plan Project (No. 2017C510002) to which the author is grateful.

\section{Conflict of Interest}

No conflict of interest.

\section{References}

1. Cai QY, Mo CH, Wu QT, Qiao-Yun Zeng, Athanasios Katsoyiannis (2007) Concentration and speciation of heavy metals in six different sewage sludge-composts[J]. Journal of Hazardous Materials 147(3): 1063-1072.

2. A Tessier, P Campbell, M Bisson (1979) Sequential Extraction procedure for the speciation of particulate trace metals. Analytical Chemistry 51(7): 844-851.

3. Thomas Hanauer, Peter Felix-Henningsen, Diedrich Steffens, Besik Kalandadze, Levan Navrozashvili, et al. (2010) In situ stabilization of metals ( $\mathrm{Cu}, \mathrm{Cd}$, and $\mathrm{Zn}$ ) in contaminated soils in the region of Bolnisi, Georgia. Plant \& Soil 341(s1-2): 193-208.

4. Ryan T (1993) Coupled fluid, electrical and chemical flows in soil [J]. international journal of rock mechanics \& mining sciences \& geomechanics abstracts 30(3):121-134.

5. Reddy KR, Parupudi US, Devulapalli SN, et al. (1997) Effects of soil composition on the removal of chromium by electrokinetics. Journal of Hazardous Materials 55(1-3): 135-158.

6. Kim SO, Moon SH, Kim KW, Seong Taek Yun (2002) Pilot scale study on the ex situ electrokinetic removal of heavy metals from municipal wastewater sludges [J]. Water Research 36(19): 4765-4774.

7. Reddy K, Cutright T (2003) Nutrient Amendment for the Bioremediation of a Chromium-Contaminated Soil by Electrokinetics. Energy Sources 25(9): 931-943

8. Al-Hamdan AZ, Reddy KR (2008) Transient behavior of heavy metals in soils during electrokinetic remediation. Chemosphere 71(5): 860-871.

9. Peng G, Tian G (2010) Using electrode electrolytes to enhance electrokinetic removal of heavy metals from electroplating sludge. Chemical Engineering Journal 165(2): 388-394.

10. Shucai Li, Tingting Li, Gang Li, Fengmei Li, Shuhai Guo (2012) Enhanced electrokinetic remediation of chromium-contaminated soil using approaching anodes. Frontiers of Environmental Science \& Engineering 6(6): 869-874.

11. Xue H, Meng F, Wang Y, et al. (2015) Remediation of chromium residuecontaminated soil by preacidification electrokinetic remediation. Research of Environmental Sciences 28(8): 1317-1323.

12. Meng F, Xue H, Wang Y, et al. (2017) Citric-acid preacidification enhanced electrokinetic remediation for removal of chromium from chromiumresidue-contaminated soil. Environmental Technology, pp. 1-7.

13. Zhang H, Gao Y, Xiong H (2017) Removal of heavy metals from polluted soil using the citric acid fermentation broth: a promising washing agent. Environmental Science and Pollution Research 24(10): 9506-9514. 